\title{
Yun Daiying's Ideology of Moral Education and Its Contemporary Implications
}

\author{
Fei Wang
}

China Jiliang University, Hangzhou, 310018, China

*Corresponding author. Email: 739650389@qq.com

\begin{abstract}
Yun Daiying's moral education thought has been of great value of the times. Even to this day, it also serves as a revelation for the ideological and political education of contemporary college students. Yun's moral education thought has a wide range of contents, mainly including advocacy that students should be careful and self-disciplined, and teachers should guide them to join society, help them to help themselves in the process of making friends, and urge them to integrate into the public. The inspiration for teachers in contemporary times is mainly in the following four areas: respecting the subjectivity of students, emphasizing the education of ideals and beliefs, guiding students to integrate into the public, and creating opportunities for practice.
\end{abstract}

Keywords: Moral education thought, Moral education in colleges and universities, Contemporary revelation.

\section{INTRODUCTION}

Yun Daiying is a Chinese proletarian revolutionist and one of the leaders of the early youth movement of the Communist Party of China. He was born in a scholarly family, and became an outstanding educator by receiving a high-quality education from an early age due to his superior family conditions. Yun Daiying has been engaged in education all his life, his educational thought is very rich, in which moral education thought occupies a place. His thought of moral education was not only of great historical significance at that time, but we can still feel its vitality today.

\section{THE MAIN CONTENT OF YUN DAIYING'S MORAL EDUCATION THOUGHTS}

As a young man, Yun Daiying broadened his vision and absorbed a wide range of ideas, including the pedagogy thought of the famous educationist Thorndike, who believed that the purpose of education was to cultivate young people who could transform society in practice, and he proposed that the education of moral cultivation must be carried out first.

\subsection{Self-discipline and Prudence}

Yun Daiying cultivated himself mainly through diary self-examination, maxims, mottos, and cautiousness, which he recommended to his friends and students.He is extremely self-disciplined. He has insisted on recording and analyzing his daily life and learning in the form of a diary since the age of fourteen.His diary is a detailed and clear record of the process of self-reflection. The content of these reflections covers a wide range of topics, ranging from daily schedules and billing plans, to career pursuits and ideal ambitions in life, which fully reflects Yun Daiying's extremely high self-requirements. In order to avoid developing bad habits during the long holiday and becoming lazy and forgetting what he has learned, Yun Daiying specially created a "Winter vacation introspection table" and recorded it in a diary to regulate his behavior during the holiday.After discovering that the "Winter holiday introspection table" can indeed play a role in supervising, Yun Daiying immediately popularized this method and called on people around him to improve their self-cultivation in accordance with this table.

Yun Daiying was able to keep the idea of "Selfrestraint and self-discipline" in mind, and always maintain a humble and cautious attitude towards people 
and things. He is more able to conduct self-analysis, be cautious, and consciously abide by various moral codes when alone. He believes that only by facing up to the shortcomings, can we truly achieve "Knowing, repentance, correction". In order to correct his mistakes and correct his behavior, Yun Daiying would even keep pushing himself through the form of scoring. For friends who have the same shortcomings and faults as himself, Yun Daiying is always strict in self-discipline, and he has changed from starting with self first, and then working outward. His behavior and attitude undoubtedly played a great role model for the people around, under his guidance, many people began to value selfexamination, self-cultivation, and eventually grew into people with lofty ideals to promote social progress.

\subsection{To Join the Community}

Yun Daiying had a strong sense of responsibility for his country and society, and he struggled all his life for the future and destiny of the Chinese nation and the freedom and happiness of the Chinese people. His life of struggling to rejuvenate China is undoubtedly a role model for countless progressive youths. He has realized his ideals and beliefs step by step and guided constantly progressive young people on the road of revolution in his actions. Yun Daiying believes that the improvement of people's moral character can not be separated from the inner self-reflection of individuals, but also from the external training and promotion of society, people should actively participate in the promotion of social development activities. He proposed that people should improve social cultivation from the following eight aspects.

First, social morality. Citizens should regard social and public affairs as their own undertakings. Second, public interest. The Chinese people who want to develop social undertakings should put the collective interests first, be selfless and seek their own reasonable interests on the premise of meeting the collective interests. Third, sincerity. If you want to get things done with others, you have to be honest with them. Fourth, be cautious. Pay close attention to the outside world and your own words and deeds, to avoid adverse or unfortunate things. Fifth, be modest. In order to win the respect of others, it is necessary to keep a modest moral character and not be conceited. Sixth, obedience. Social solidarity requires obedience. The obedience here does not mean obeying power, but obeying the truth and obeying the majority. Seventh, be polite. To engage in social undertakings, one should have good cultural attainments. Eighth, altruism. Yun Daiying hopes that citizens can reach the realm of serving the people, and they can always take social responsibility as their responsibility no matter what job they are in.

\section{3. "Help Yourself and Help Others"}

Yun Daiying advocates making friends for self-help, by learning from friends to achieve the purpose of "Selfhelp", and making progress with friends in the process of learning from friends so as to achieve the purpose of "Helping others".Yun Daiying attaches great importance to making friends with like-minded people. $\mathrm{He}$ will always seriously consider the opinions and suggestions put forward by friends, and promptly correct shortcomings and make up for deficiencies. At the same time, he will also point out the shortcomings of his friends and help them to correct their shortcomings and get promoted. Yun Daiying believes that helping others is also one of the ways to shape noble qualities. People can constantly hone their will in the process of helping others, and they will no longer be easily induced by bad things.

Yun Daiying's idea of "Self-help and help others" not only influenced his friends around him, but also continuously promoted more people to help each other through the establishment of mutual aid club for selfcultivation. Yun daiying's mutual aid club takes "Brainpower, self-help and help others" as its tenet. Its members always supervise and encourage each other, and constantly regulate their words and deeds with high moral codes. Focusing on "Benevolence, wisdom and courage", Yun Daiying put forward a moral standard centered on "Virtue" and formulated about eight precepts. The mutual-aid club holds a meeting every day, in which criticism and self-criticism are carried out among members, and the ideological level of the members is generally improved in the remarks. In addition, Yun Daiying also summed up the art of helping others based on personal experience.

\subsection{Integrate into the Masses}

Yun Daiying believed that many intellectual youths were often too proud of their status to integrate well with the masses. He was unable to cooperate well with others and lacked the "cultivation of mass life. Only by collaborating with each other and mobilizing the masses can we create a great synergy. This was the only way to effectively change China's poor, backward, and corrupt society. Yun believed that integration with the masses must begin with oneself, "refrain from arrogance and vices," and always be peaceful and humble in one's dealings with others. He should be open and courteous to others. Only after others feel their sincerity can they return it with "the most sincere heart". In the process of interacting with others, one should always think of others, disregard fame and fortune, and be self-reliant. Yun also suggested that students should always reflect on themselves when dealing with others. Once they find a fault, they should make every effort to correct it. At the same time, they should accept the advice of others 
and give timely advice to their friends. In this way, "no fault is unknown, and no knowledge is uncorrected". It is not easy for students who are born in better circumstances to truly integrate themselves into the masses, so Yun Daiying attaches great importance to fostering the awareness of the masses among young people and enables students to have a deep understanding of the people's situation, to improve their ability to mobilize the masses and fight alongside them by conducting social surveys and other forms.

\section{CONTEMPORARY REFERENCE OF YUN DAIYING'S MORAL EDUCATION THOUGHTS}

Yun Daiying's thought of moral education has successfully guided numerous men of insight to combine personal cultivation with social progress, and has played an indelible positive role in the success of China's revolutionary cause. Even in contemporary times, Yun Daiying's moral education thought also has certain reference function for the ideological and political education of college students.

\subsection{Respect the Status of Students as the Main Body and Improve Their Self-education Ability}

At present, the importance of students' selfeducation is neglected in ideological and political education in colleges and universities. Contemporary college students live in an open and free information society, and their cognitive approaches are constantly broadened, so it is difficult for them to accept the indoctrination model of moral education.

The main thread of "Self-government" runs through the contents of Yun Daiying's thought of moral education, such as self-discipline, self-examination and self-help. For both intellectual education and moral education, Yun Daiying opposed the traditional teaching method of injection education, and advocated respecting students' subjective status so that students can acquire the ability of self-education. This points out the direction for today's ideological and political education.

Colleges and universities should respect the subject status of students, pay attention to arouse the selfconsciousness of students, and adjust the ways and means of ideological and political education in time, so as to fully arouse the enthusiasm and initiative of the educational object. Educators should be aware of the ideological reality of the objects of education. On the one hand, we should conduct heuristic guidance on the basis of respecting the personality and rights of the objects of education, on the other hand, according to the differences of students' cognitive level, family environment and physical and mental quality, we can give classified guidance and teach students according to their aptitude, so that the internal moral needs of the educational objects can be stimulated, and they take the initiative to internalize their ideological and moral cognition.

\subsection{Attach Importance to the Education of Ideals and Beliefs and Enhance the Awareness of Social Responsibility}

While the market economy promotes the economic development of China, all kinds of complicated ideological trends also bring some negative effects to college students' thoughts. College students, whose minds are not yet fully mature and who lack accurate judgments about things, present prominent problems such as lack of ideals and beliefs, money worship, hedonism, and extreme individualism, and lack the lofty ideals and firm beliefs in Marxism to fight for the construction of the motherland. In this regard, we can draw some lessons from Yun Daiying's moral education.

Yun Daiying integrated patriotic education into his moral education, guiding his students to devote themselves to the cause of society and to save the country. He believes that young people should not only improve self-cultivation to transform the society, but also constantly sublimate their value cognition in the process of transforming the society.

First of all, colleges and universities should make college students consciously establish Marxist belief on the basis of improving their discernment ability. Only when college students have the ability to distinguish right from wrong and have their own judgment on things can they not be easily invaded by those wrong thoughts. Teachers should teach students how to think and judge, and build their beliefs on the basis of their full cognition. Secondly, we should strengthen the education of socialist core values of college students and enhance their sense of social responsibility. To improve the patriotic enthusiasm of college students is an indispensable step to cultivate their sense of social responsibility. The university can cultivate their sense of ownership by organizing some campus activities with the theme of social hot events.

\subsection{Guide Students to Integrate into the Masses and Cultivate the Culture of Life of the Masses}

At present, many families and schools only focus on the material needs of their children to meet the onesided emphasis on academic achievement, ignoring their mental health and moral education. Such a social environment easily makes them form extreme individualistic values, take the view of "Money first" as the standard of all measurement, and ignore personal moral cultivation and the observance of social morality. 
Yun Daiying, who wrote specifically about the necessity and basic requirements of self cultivation in mass life, argued that the power of the individual is not enough to create a new world, and that only by joining the masses and uniting can we change society and save the country. From today's point of view, the so-called group cultivation means being able to unite and cooperate with others under the guidance of collectivist values, putting collective interests first.

The aim of ideological and political education in colleges and universities is to guide students to integrate into the socialist family, and finally to promote social development through collective solidarity and cooperation. Specifically, it can provide more opportunities for students to participate in collective activities, in which they can feel the power of unity and cultivate their ability to communicate and cooperate with others.

\subsection{Create Practical Opportunities and Consolidate Educational Achievements}

In the traditional ideological and political education, educators have always separated themselves from practice and only paid attention to inculcating students with theoretical knowledge. As a result, although some educatees have a certain moral cognition, they often show weak will and inconsistent knowledge and behavior in daily life.

Yun Daiying attaches great importance to practice, he believes that empty talk would mislead the country, and that saving the country should be carried out in practice. We should start with what we can do around us. He led the students to carry out practical activities, so that students in practice to understand the national conditions, enhance capacity, and ultimately hone a higher moral cultivation. Only through practice, can college students successfully externalize the internalized theory into individual action. The ultimate goal of ideological and political education in colleges and universities should be practice.

Practice can also enable students to consciously accept the theory of education, thus consolidating the achievements of ideological and political education. The ideological and political education in colleges and universities needs to change the boring theory indoctrination and guide the students to accept ideological and political education consciously in practice, so as to cultivate talents who meet the needs of the society. Colleges and universities should strengthen practical teaching and pay attention to students' personal experience in practical activities. Students can externalize the perceptual understanding of moral education into concrete behaviors in the process of participation, and practice civic moral norms in daily life through carrying out and participating in practical activities, making use of college students' campus cultural activities, volunteer activities, social practice and other ways.

\section{CONCLUSIONS}

The contemporary college students are in the new era that China is approaching the center of the world stage and making greater contributions to mankind. They are faced with both enormous opportunities and equally severe challenges, which brings forward higher and newer requirements for college moral education and the quality of college students. In the years when Yun Daiying lived, the society was in violent turmoil, and the country and the nation were in peril. Under the background of this era, he took it as his duty to explore the way to save the country all his life. Under the guidance of Marxism, he combined his youth movement experience with his educational practice, and gradually formed and developed his moral education thought.

Yun Daiying's thought of moral education has its historical value, and certain reference significance and reference value for the further development and practice of moral education thought in today's society. By summing up the contents of his moral education thought, this paper explores the concrete ways to integrate his moral education thought into contemporary moral education practice, so as to better train the excellent successors called for by the new era, and lay a solid talent foundation for realizing the Chinese dream of the great rejuvenation of the Chinese nation.

\section{REFERENCES}

[1] Yun Daiying. Yun Daiying's Diary [M]. Beijing: Party School of the Central Committee of the Communist Party of China Press. 1981.

[2] Li Liangming, Zhong Detao. Yun Daiying's Chronology $[\mathrm{M}]$. Wuhan: Huazhong Normal University Press. 2006.

[3] Wang Hongshang. Research on Yun Daiying's Youth Education Thought [D]. Yunnan Normal University, 2016.

[4] Li Yingying. Yun Daiying's view of youth ideology and political education and contemporary revelation [D]. Huazhong Normal University, 2019.

[5] Zhang Wei, Lin Shendan. The historical characteristics of Yun Daiying's youth education thought and its contemporary value [J]. Party History Bo Cai (Theory),2016(07):17-19.

[6] Li Bing. Yun Daiying's educational thought and its practical significance $[\mathrm{J}]$. Pinnacle Classics, 2020(08):36-38. 
[7] Xu Jigui. Exploring Yun Daiying's ideology of youth education and its practical significance [J]. Knowledge Window (Teacher's Edition), 2019(05):75.

[8] Xue Yan. Young Yun Daiying's thought of moral cultivation and its practice [J]. Journal of Changsha Civil Affairs Vocational Technology College, 2020,27(02):33-36. 